\title{
Understanding the implications of current health trends on the aroma of wet and dry cured meat products
}

\author{
Mónica Flores. \\ Instituto de Agroquímica y Tecnología de Alimentos (IATA-CSIC) Avda. Agustín \\ Escardino 7, 46980 Paterna, Valencia, Spain
}

*Corresponding author. Tel.: +34 96 3900022; fax: +34 963636301

E-mail address: mflores@iata.csic.es (M. Flores).

\begin{abstract}
Meat product aroma is affected by various meat processing factors. In this review the main biochemical reactions involved in the development of meat product aroma (wet, dry cured and fermented) are fully described. Moreover, the different techniques used for key aroma elucidation in meat products are defined. The aroma compounds present in wet, dry cured and fermented meat products (sausage and whole piece) have been summarized. The mechanisms of aroma formation during the manufacture of cooked and dry/fermented meat products are described. In wet meat products the main reactions described are lipid degradation (oxidative reactions), Maillard reactions, Strecker degradation, and thiamine degradation while in dry meat products are; lipid degradation (oxidative reactions), thiamine degradation, microbial carbohydrate fermentation and microbial metabolism including complex interactions among them such as the amino acid degradation produced by lipid oxidation products. Finally, the effect of current health trends such as salt, fat and nitrifying content reduction on the development of meat product aroma is explained.
\end{abstract}

Keywords: volatile; cured; fermented; cooked; aroma. 


\section{Introduction}

Aroma development in meat products is a complex process produce by the interactions of many factors; raw material and ingredients by contributing to major precursors (proteins and lipids), presence of additives (salt and curing agents), to finally, the manufacture process (wet vs dry) (Flores and Olivares, 2015). So, all these factors are interrelated and essential for aroma development and contribute to differentiate the aroma among meat products.

Many different cured meat products are manufactured worldwide (Feiner 2006) but in terms of manufacture process two major groups may be considered: dry-cured and wet-cured products. Meat products accounts for $15 \%$ of the total food market worldwide in 2016 however, due to increased health concerns and desire for meat alternatives (Frank, Oytam, \& Hughes, 2017) consumer demand has stagnated (Brinckmann, 2017). Dry curing is essentially represented by dry cured hams and fermented sausages (Toldrá and Hui, 2015). Dry-cured hams are manufactured in many countries such as Country style ham in USA, Jerky in South America, Serrano and Iberian hams in Spain, Parma, San Daniele, Toscano and Nero Siciliano in Italy, Bayonne ham in France, Spekeskinke in Norway, Hangikjöt in Iceland, Jinhua ham in China and many others (Toldrá and Hui, 2015). Fermented meat products include dry long ripened sausages (salami, saucisson, pepperoni, salchichon, sausage) and semidry sausages (summer sausage, cervelat) (Toldrá and Hui, 2015, Toldrá and Flores 2014) and China Lap cheong. Dry meat products are manufactured with meat mostly from pork and beef but also other species are sometimes used such as lamb, duck, etc. They are dried and ripened for a relatively long period of time for dehydration and biochemical and microbiological development of flavor. The main representatives of wet-cured are cooked ham and frankfurters. These products are also produced worldwide (Feiner 2006, Flores, 2016) and a pickle or brine solution is added to the product by injection or mixing with the mince. These products are generally cooked, optionally smoked, and are shorter in processing time than the former (Feiner 2006, Toldrá and Flores, 2006). In wet and dry cured meat products in addition to different ingredients and additives (Tarté, 2009), spices and condiments are often used to modulate flavor. These examples of meat products are considered in this chapter, with special attention to aroma development. The composition and contents of the most typical wet and dry cured meat products is shown in Table 1.

Regarding aroma, the trends in volatile studies is to report the changes produced in volatile profile due to different factors and the identification of hundreds of volatile compounds (Flores, 2017). Nevertheless, only a small percentage of them contribute 
directly to the aroma (Dunkel et al., 2014) as they must be at a concentration above their olfactory threshold to be odor active. Only these aroma active compounds are essential to the final sensory characteristics. So the elucidation of key aroma compounds is a major area of interest although a major focus for the meat product industry is to deliver a desirable and well-balanced flavor throughout the manufacture process. In this sense, the latest current health trends such as salt, fat and nitrifying reduction has become essential for processors. Reducing salt has become an issue to the meat industry due to the relation of salt intake and incidence of hypertension resulting in initiatives to reduce salt in food (Desmond, 2006, Jaenkea, Barzia, McMahona, Webster \& Brimblecombe., 2017). Fat reduction and substitution of saturated fats to obtain improved fatty acid profile is a major task (Barendse, 2014) and produce an important effect not only on aroma development in meat products (Olivares, Navarro \& Flores, 2011) but also on flavor release (Frank et al., 2010, Frank, Appelqvist, Piyasiri, Wooster, \& Delahunty, 2011). This trend has produced an increase in the development of different functional meat products based on vegetable oils, soy, fiber, etc. (Fernández-Ginés, Fernández-López, Sayas-Barberá, \& Pérez-Alvarez, 2005, Zhang, Xiao, Samaraweer, Lee, Ahn, 2010). Furthermore, the generation of nitrosamines in meat products derived from nitrite and secondary amines is of safety concern due to their carcinogenic potential (De Mey, De Maere, Paelinck, Fraeye, 2015) and the efforts are based on the search of alternatives to nitrites (Gassara, Kouassi, Kaur Brar \& Belkacemi, 2015, Alahakoon, Jayasena, Ramachandra \& Jo, 2015). Thus, reformulation strategies are likely to have important impacts on the sensory characteristics and on the development of the desirable aroma.

Flavor generation by wet and dry manufacture is part of the process and a natural way of producing aroma in meat products. This has become a consumer need in contrast to the direct addition of flavorings to flavorless meat products. So, the aim of this review is to provide the knowledge of the formation of desirable aroma compounds during the manufacture of wet and dry cured meat products. Finally, the effect of current health trends such as salt, fat and nitrifying content reduction on the development of meat product aroma is explained.

\section{Biochemical reactions involved in aroma generation in meat products}

Taken into account the different process of manufacture in wet and dry cured meat products, the mechanisms involved in aroma development have common reactions but others may be differentiated. In cooked meat products the main mechanisms involved are lipid degradation (oxidative reactions), Maillard reactions-Strecker degradation, and 
thiamine degradation (Mottram, 1998, Vermeulen, Gijs and Collin 2005, Flores, 2017). In addition, many of these pathways are interconnected. In dry cured meat products the main reactions are the lipid degradation (oxidative reactions), the microbial fermentation of carbohydrates (sugars such as dextrose, sucrose, lactose and maltodextrin) and finally, the enzymatic hydrolysis of proteins and lipids generating aroma precursors (free amino acids and fatty acids) that are the substrates of chemical reactions and microbial metabolism (Flores \& Olivares, 2015). The main chemical classes of volatile compounds detected in meat products, their aroma contribution, and their mechanism of formation are indicated in Table 2.

\subsection{Lipid oxidation reactions}

Unsaturated fatty acids are susceptible to oxidation under cooking and especially, phospholipids rather than triacylglicerides (Elmore, Mottram, Enser, \& Wood, 1999, Frank, Kaczmarska, Paterson, Piyasiri, \& Warner, 2017). The oxidative reactions generate a wide number of volatile compounds, aldehydes, ketones, alcohols, aliphatic hydrocarbons, acids and esters (Mottram, 1998, Elmore, Campo, Enser, \& Mottram, 2002, Campo, Nute, Wood, Elmore, Mottram, \& Enser, 2003, Frank et al., 2016). These compounds are responsible for the cooked meat aroma, rancid notes during storage periods, and cured aroma of meat products (Toldrá \& Flores, 2006). The species character; pork, lamb or beef is attributed to the lipid unsaturated profile as contributor to aroma compounds (Rodbotten, Kubberod, Lea, \& Ueland, 2004; Watkins, Frank, Singh, Young, \& Warner, 2013).

As seen in Table 2, alcohols, ketones and aldehydes are considered minor contributors to meat product aroma due to their high odor threshold values in comparison to other compounds such as furans, pyrrol, sulfur compounds, etc., although they contribute to characteristic aroma notes depending on the chemical structure (rancid, grass, green, citrus, fried, fatty) (Table 2). It is also important to remark that in many cases their concentrations are above their odor detection threshold being key aroma contributors.

\subsection{Maillard reaction-Strecker degradation}

The Maillard reaction is initiated by the reaction of a reducing sugar and amino compound in cooked meat products as it is favored by high temperatures and low moisture. This will be the case of wet cured products while in dry cured products it is necessary to have long drying times and low water activities to favor this reaction.

The formation of flavor compounds depends on the type of sugar and amino acid involved together with reaction conditions. The degradation of ribonucleotides during the conversion of muscle to meat produces ribose that takes part in the Maillard 
reaction as the reducing sugar (Koutsidis et al., 2008). As well the amino group of free amino acids generated from hydrolysis of peptides and proteins participate in the reaction. Thus, the dry curing process acts as a major source of amino groups by generating free amino acids through proteolysis in contrast to wet curing (Toldrá \& Flores, 2006).

The different volatile compounds generated at the beginning of the reaction include; furanones, furfurals, dicarbonyl compounds and others. The progression of the reaction with reactive compounds such as amines, amino acids, hydrogen sulfide, thiols, ammonia, leads to the generation of different heterocyclic compounds (pyrroles, pyrazines, oxazoles, thiophenes, thiazoles) characterized by low odor threshold and high aroma impact (Mottram, 1998, Toldrá \& Flores, 2006) as indicated in Table 2.

The Strecker degradation of amino acids is related to the Maillard reaction. The dicarbonyl compounds originated from carbohydrate degradation in the Maillard reaction produce a deamination and decarboxylation of the amino acid and finally, produce an aldehyde with one fewer carbon than the original amino acid and an alphaaminoketone (van Boekel, 2006).

\subsection{Relation of Maillard reaction products with lipid oxidation reactions}

Recent studies have demonstrated that the conversion of amino acids into Strecker aldehydes, a-keto acids, and amines can be also produced by lipid-derived free radicals and carbonyl compounds derived from lipid oxidation reactions (Zamora, \& Hidalgo, 2004, 2011, Hidalgo and Zamora, 2015). The generation of these compounds is interconnected and their formation is a function of the oxidized lipids, amino acid involved and the processing conditions $(\mathrm{pH}$, aw, time, temperature) that modify their production in the meat product and therefore modify the final flavor (Zamora, Navarro, Aguilar, \& Hidalgo, 2015).

\subsection{Thermal thiamine degradation}

Thiamine (vitamin B1) degradation by thermal treatment produces the generation of aroma compounds including furans, thiophenes, thiazoles and aliphatic sulfur compounds although its production in meat products depends on many factors such as temperature, time, $\mathrm{pH}$, matrix composition, etc. (Thomas, Mercier, Tournayre, Martin \& Berdagué, 2015, Flores, 2017). These compounds have very low odor threshold and are very important for meat product aroma contributing to grassy, meaty, green, and roasted aroma notes (Table 2 ). Although these compounds are easily detected by the human nose they are difficult to analyze by conventional instrumental techniques such as GC-MS due to their very low concentration at ppt levels. 


\subsection{Microbial fermentation of carbohydrate}

The microbial fermentation of carbohydrates (dextrose, sucrose, lactose and maltodextrin) in meat products produces the formation of organic acids such as lactate and acetate, contributors to meat product sourness. This carbohydrate fermentation is mainly achieved by lactic acid bacteria resulting in a $\mathrm{pH}$ drop in fermented meats (Flores, 2017) while coagulase negative staphylococci are involved in the bacterial formation of aroma compounds (Ravyts, Vuyst, \& Leroy, 2012). The catabolism of pyruvic and lactic acids by lactic acid bacteria (Liu, 2003) produces compounds such as acetic acid, formic acid, ethanol, acetaldehyde, 2,3-butanedione (diacetyl), 3hydroxy-2-butanone (acetoin) and 2,3-butanediol that are responsible for specific aroma notes (Table 2).

\subsection{Microbial metabolism of aroma precursors (free amino acids and fatty acids)}

Lipolysis and proteolysis are essential biochemical reactions for flavor development (Flores \& Olivares, 2015) as they provide precursors, free amino acids and fatty acids (Zanardi, Ghidini, Battaglia, \& Chizzolini, 2004, Corral, Leitner, Siegmund, \& Flores, 2016), which will be further degraded to produce aroma compounds.

Free fatty acids generated are degraded during fermentation processes by the activity of microbial enzymes through lipid $\beta$-oxidation reactions, producing short-chain fatty acids and $\beta$-ketoacids. These short chain fatty acids may contribute to pungent and penetrating odor notes in meat products (Table 2). Then, the $\beta$-ketoacids are degraded to methyl ketones through microbial (mainly Staphylococcus and Penicilliun) decarboxylation reactions that are further degraded to secondary alcohols (Montel, Masson, \& Talon, 1998, Ravyts et al., 2012). These secondary alcohols have less odor impact due to their high threshold. They may contribute to greenish, woody, fatty, floral and mushroom notes while methyl ketones have low odor threshold and contribute to animal fat and fruity, fatty odors (Table 2).

Nevertheless, the microbial degradation of free amino acids by decarboxylation and deamination produces ammonia and therefore, a rise in $\mathrm{pH}$ during fermentation (Toldrá, Sanz \& Flores, 2001). Whereas the transamination and decarboxylation of branched amino acids (valine, isoleucine, and leucine), produces the respective branched aldehydes, alcohols, and/or acids that produce malty and pungent odors (Table 2) (Yvon \& Rijnen, 2001, Ravyts et al., 2012). Other amino acids (phenylalanine, threonine, tryptophan, tyrosine, etc.) are also transformed into their respective aldehydes, such as phenylacetaldehyde from phenylalanine and indole compounds from tryptophan. The degradation of the sulfur amino acids, cysteine and methionine, 
produces sulfur volatile compounds (Ardö, 2006). Methionine produces methionol, methional and oxidation products such as dimethyldisulfide and dimethyltrisulfide. These compounds are characterized by very low odor threshold and meat-like, sulfurous, cabbage, onion odor notes (Table 2). Microbial enzymes involved in cysteine degradation release hydrogen sulfide involved in other oxidation reactions producing potent aroma sulfur compounds. In addition, the production of acids and alcohol compounds from amino acid catabolism during microbial fermentation are precursors for ester compounds formed by the esterase activity of staphylococci present in meat products (Ravyts et al., 2012). The main ester compounds identified in fermented meat products are short chain ethyl esters $(\mathrm{C} 1-\mathrm{C} 10)$ that contribute to fruity notes (Table 2$)$.

\section{Measuring aroma in meat products-Olfactometry analysis}

Key aroma compounds contributing to the aroma of meat products should be isolated and identified among the hundreds of volatile compounds present in the meat product. The first step in volatile isolation is the selection of the appropriate technique to extract compounds from the meat matrix or the headspace surrounding the meat product. However, the volatile profile depends on the isolation technique selected (Corral, Salvador \& Flores, 2015). Solvent extraction and distillation, thermal desorption and supercritical fluid extraction are widely used due to their ability to extract potent odorants present in very low concentrations but their use may produce artefact formation due to heat, decomposition of compounds and loss of highly volatile compounds. Therefore, in solvent extraction techniques, the use of vacuum distillation and low temperatures has allowed the reduction of artefacts formation (d'Acampora Zellner, Dugo, Dugo, \& Mondello, 2008). Currently, headspace techniques are frequently used due to their simplicity, elimination of solvent use and heat avoiding artefact formation (Corral et al., 2015). Dynamic headspace techniques such as purge and trap, solid phase microextraction (SPME), Stir bar sorptive extraction (SBSE) (Jelén et al., 2012) are widely used compare to static headspace due to their high sensitivity although, the volatile profile obtained depends on the trapping material used (Flores and Corral, 2017).

In addition, aroma compound contribution is generally obtained by the calculation of the odor activity value (AOVs) through the ratio of odorant concentration to its odor threshold (Grosch, 2001). However, odor threshold is highly dependent on matrix composition so different odor thresholds are calculated in water, air and oil (Van Gemert, \& Nettenbreijer, 2004). In many foods, aroma compounds with high OAVs are essential for the aroma but these compounds are not present individually and 
interactions among them produce a large loss of sensory properties of the individual constituents.

Nevertheless, the elucidation of odor-active and main odor-impact compounds in meat products requires the use of olfactometry techniques in order to determine which compounds have aroma among all the volatiles present. This is performed by the screening of the compounds eluted from a gas chromatograph (olfactometry GC-O) by using a sniffing port where the human nose is used as a detector (Delahunty, Eyres, \& Dufour, 2006). In GC-O, the end of the chromatographic column is split into different detectors; MS or FID and olfactory port. However, the olfactory result depends on panelist performance, training and the use of different olfactometry methods; dilution, detection frequency and direct intensity techniques (Delahunty et al., 2006). The results are represented in an aromagram that includes the instrumental detector signal and the aroma description, intensity or duration reported by panelists (Flores, Grimm, Toldrá, \& Spanier, 1997).

The use of these techniques in meat products has allowed the identification of key aroma compounds (Flores \& Olivares, 2015, Flores, 2017) and the establishment of their contribution to sausage aroma at different stages of processing (Olivares, Navarro, \& Flores, 2009). Although interactions between volatile aroma compounds and volatile-matrix should not be forgotten as these interactions are essential for aroma perception like peptide and protein (Martínez-Arellano, Flores \& Toldrá, 2016), and lipid interactions (Frank et al., 2010, 2017).

\section{Meat products aroma}

Flavor development in meat products depends on product composition and processing conditions (Toldrá \& Flores 2006). Therefore, many studies have demonstrated the effect of processing parameters on volatile composition. Among the hundreds of volatile compounds several of them have been identified as key aroma contributors in cured meat products (Figure 1). Figure 1 indicates the main aroma compounds identified in cured meat products and their odor contribution. The aroma of cooked ham (Thomas et al., 2013, 2014; Benet et al., 2016), cooked sausage (Chevance, and Farmer, 1999a,b), dry cured ham (Flores et al., 1997; Carrapiso, Jurado, Timón, \& García, 2002; Song \& Cadwallader, 2008; Theron et al, 2010; Xiao-Sheng et al., 2014) and fermented sausages (Stahnke 1994, 1995; Meynier, Novelli, Chizzolini, Zanardi, \& Gandemer, 1999; Schmidt \& Berger 1998a, 1998b; Chevance et al 2000; Blank et al. 2001; Marco, Navarro \& Flores, 2007; Söllner \& Schieberle, 2009; Gianelli, Olivares \& Flores, 2011; Olivares, Navarro \& Flores, 2011; Corral et al., 2016) has been elucidated. 
The aroma wheel (Figure 1) represents the different aroma descriptors identified in meat products and the volatile compounds responsible for these odor notes. In this sense, aldehydes and ester compounds contribute to green, fatty and fruity odors, sulfur and nitrogen compounds produce meaty, onion, roasted and nutty odors, and the presence of terpenes produce the typical spicy aroma notes as derived from the spices often added in manufacture. The combination of odors produces the typical meat product aroma as many of them have been identified in the different types of meat products although none have been attributed to the characteristic "cured aroma".

The comparison of uncured and cured aroma was firstly studied by Ramarathnam, Rubin, \& Diosady, $(1991,1993)$ who reported the significant contribution of carbonyl compounds to the flavor of uncured meat. Recently, an effect of nitrite on cooked ham aroma has been determined and it produces a strong inhibition of hexanal formation affecting ham flavor by altering the perception of sulfur key odor compounds (Thomas et al., 2013, 2014). Among the sulfur compounds identified by olfactometry analysis, 2methyl-3-(methyldithio)furan was assigned as a key odor compound for cooked ham aroma, although its concentration was not affected by the presence of nitrite. However, the generation of aldehydes during oxidation reactions was essential for aroma perception; when nitrite is not used the high generation of aldehydes masks the aroma of sulfur compounds as they are the key aroma compounds in nitrite cured products (Thomas et al., 2013). In conclusion, the use of nitrite as curing agent could not be attributed to the formation of a specific cured aroma compound but it produces a balance in odor perception.

Taking into account the impact in meat product aroma of compounds contributing to specific odor notes at very low concentrations (low threshold), several sulfur and nitrogen compounds have been isolated and identified in meat products. These compounds mainly originated from Maillard reactions and thiamine degradation (Table $3)$.

In cooked meat products, the intense meaty and cooked ham odor have been attributed to the presence of 2-methyl-3-furanthiol, 2-methyl-3-(methyldithio)furan and bis(2-methyl-3-furyl) disulfide compounds originated from the thermal degradation of thiamin (Thomas et al., 2014). This fact was observed in model cooked hams where the concentration of thiamin was related to the amount of 2-methyl-3-furanthiol (Thomas et al., 2015). However, the contribution of the sulfur amino acid cysteine was not observed in the ham models revealing a low contribution of amino acid degradation reactions to the aroma. The impact of intramuscular fat and polyunsaturated fatty acids on aroma should not be forgotten as high intramuscular fat hams have higher aroma compounds from Maillard reactions related to roasted notes than low intramuscular fat 
hams (Benet et al., 2016, Frank et al., 2017). Nevertheless, the use of subcutaneous fat and back-fat in cooked meat products like cooked sausages produces aroma compounds with characteristics odor notes like hexanal (green odor), (E,E)-2,4decadienal (stale, meaty, oily odor) and 1-octen-3-one and 1-nonen-3-one (mushroom odors) (Chevance and Farmer, 1999).

In dry cured meat products a specific compound producing cured odor has not been identified. Due to the long ripening times that favors the generation of precursors and the low water activity that favors lipid oxidation and Maillard reactions, many sulfur and nitrogen compounds have been identified as aroma impact compounds (Table 3 ). In this case, thermal degradation reactions are not produced although the compound derived from thiamine degradation, 2-methyl-3-furanthiol, has been detected in dry products (Carrapiso et al., 2002) indicating that this reaction may be also present in this type of products. The typical green grassy odor notes in hams were attributed to the presence of hexanal, 3-methylbutanal, 1-penten-3-ol (Flores et al., 1997), nutty and roasted notes were produced by pyrrole, 2-acetyl-1-pyrroline, dimethylpyrazine and tetramethylpyrazine (Theron et al, 2010, Xiao-Sheng et al., 2014) while several sulfur compounds such as dimethyl-disulfide, methanethiol and 2-methyl-3-furanthiol are key aroma contributors in dry cured ham (Song and Cadwallader 2008, Theron et al, 2010, Carrapiso and others 2002).

In addition to the mechanisms indicated above, fermented sausage aroma is produced by microbial metabolism (Flores \& Olivares 2015) and microbial degradation of amino acids is a source of aroma compounds like straight chain sulfur compounds, thiols, pyrazines and pyrroles (Table 3). Many sulfur and nitrogen compounds have been identified although many of the identified sulfur compounds may derive from the use of spices as ingredients. Sulphur compounds produce vegetable and garlic notes but also meaty odors when derived from amino acid degradation like methional, dimethyl disulfide and dimethyl trisulfide (Flores \& Olivares, 2015). Moreover, pyrroles and pyrazines have been also identified as key aroma compounds producing toasted and nutty odors. Especially significant is the contribution of 2-acetylpyrroline to roast and popcorn odors in dry meat products (Söllner \& Schieberle, 2009).

The use of spices as ingredients in sausage products (cooked and dry) produces an important effect on aroma in addition to smoking process that contributes to phenol and methoxyphenol aroma compounds. Terpene compounds derived from black pepper, paprika, oregano, etc. impart fruity, green, herbal, pine, pungent aroma notes to meat products while sulfur compounds produce unpleasant and garlic notes when derived from spices (garlic, onion, mustard, nutmeg) (Figure 1). 


\section{Effect of current health trends on aroma of meat products}

Several studies have revealed the effect of salt, fat and nitrifying reduction on chemical characteristics and sensory properties of meat products (Aaslyng, Vestergaard \& Koch, 2014) and indicated appropriate strategies to be used in salt reduced meat products (Inguglia, Zhang, Tiwari, Kerry, \& Burgess., 2017). Several of them studied the strategies to reduce salt and fat, although nitrite reduction is a difficult task (Muguerza, Gimeno, Ansorena, \& Astiasarán, 2004; Inguglia, et al., 2017; Alahakoon, Jayasena, Ramachandra, \& Jo, 2015). However, few of them have paid attention to key aroma compounds produced during reformulation.

\subsection{Salt reduction}

The effect of salt reduction on the aroma of meat products and especially on odoractive compounds has been scarcely studied. Many reports have indicated the changes on the abundance of volatile compounds in different products such as dry sausages (Alves dos Santos et al., 2015), dry cured goose (Ying et al., 2016) although few of them have demonstrated the effect on key aroma compounds.

In cooked meat products several studies have reported the effect of salt reduction and substitution with $\mathrm{KCl}$ and other strategies on the sensory characteristics of cooked ham (Tamm, Bolumar, Bajovic, \& Toepfl, 2016). Regarding aroma compounds, studies have been done in dry meat products due to their high salt content (Table 1) and therefore, its reduction will not only affect safety but also the organoleptic characteristics. In dry cured ham, the effect of salt reduction has shown controversial results due to the different strategies used to reduce the salt content. Salt reduction and substitution with $\mathrm{KCl}$ promoted formation of lipid-derived aldehydes, Strecker aldehydes, alcohols, and methyl-branched aldehydes in Jiuan ham (Zhang et al., 2016) while a reduction in volatile compounds abundance was observed in Slovenian dry hams with reduced salt content without using substitutes (Škrlep et al., 2016). In reduced salt Spanish dry hams, high significant amounts of lipid-derived volatiles such as hexanal were detected but the use of calcium and magnesium salts as substitutes produced an increase in Strecker aldehydes and alcohols (Armenteros, Toldrá, Aristoy, Ventanas, \& Estévez, 2012). However, there are no reports regarding the effect of salt reduction on key aroma compounds.

In dry fermented sausages, salt reduction has shown an effect on aroma by reducing sulfur and acids and increasing aldehyde compounds (Corral, Salvador \& Flores, 2013). The salt reduction produced a decrease in the aroma compounds; this included dimethyl trisulfide, 3-methyl thiophene, 2,3-butanedione, 2-nonanone and acetic acid therefore, decrease cooked, onion, butter and vinegar odors. In contrast, key aroma 
aldehydes (hexanal, heptanal, 2-nonenal, pentanal) increase and thus, produce the increase in herbal, grass, green odors. Salt reduction decreased the aroma intensity and the consumer acceptance of reduced salt fermented sausages (Corral et al., 2013).

\subsection{Fat content}

Reduction of fat content in whole meat products has not been studied as fat content will depend on raw material characteristics in contrast to sausage and minced meat products where fat is used acting as a filler. In the minced products fact acts stabilizing the protein network and prevents shrinking during cooking. Fat from different anatomical locations of pork is used (loin, belly, neck) due to unsaturated fatty acid content. The fat content in cooked sausages is very variable from 5 to $30 \%$ (Flores, 2016). Thus, fat reduction studies regarding aroma compounds have been mainly performed on sausage (wet and dry cured) products. Nevertheless, the effect of intramuscular fat content (IMF) and composition of cooked ham aroma has been studied (Benet et al., 2016). These authors found that cooked hams with high IMF content had high aroma compounds derived from Maillard reactions and thiamine degradation reactions. This ham was related to the amounts of 2-methyl-3(methyldithio)furan and guaiacol producing meaty and ham-like odors, respectively. But the high levels of polyunsaturated fatty acids contained in low IMF hams produced high oxidation aroma compounds like hexanal and (E,E)-2,4-decadienal, contributors to rancid and fatty odors. These compounds probably mask the roast and aged fat odors that contribute to the richer and better balanced cooked ham flavor observed in high IMF hams (Benet et al., 2016).

The reduction of fat content and the use of fat replacers have been studied in different types of sausages. In salami and frankfurter, fat reduction produces an increase in release to the headspace of volatiles but the use of carbohydrate fat replacers delay the release of specific volatile compounds although it depends on volatile chemical structure and the carbohydrate used as replacer (Chevance and Farmer, 2000). However, these authors indicated that the changes in volatile release may be produced by structural changes in the meat product or binding processes. In addition, the reduction of fat in frankfurter has been shown to produce an increase in perception of several smoky odors produced by compounds including 2-methoxy-4-methylphenol (4methylguaiacol), 2-methoxy-4-propylphenol (4-propylguaiacol), and 2,6dimethoxyphenol (syringol). Also, the intensity of odors such as spices, green, pine and floral due to the compound a-pinene and linalool, were increased in low fat frankfurters (Chevance and Farmer, 1999b). 
In dry fermented sausages fat reduction produces a decrease in the generation of lipid derived volatile compounds (Olivares et al., 2011). In term of key aroma compounds, fat reduction produced a decrease of hexanal, (E)-2-nonenal, (E,E)-2,4-nonadienal, ethyl butanoate and 1-octen-3-ol and thus, reduced the green, medicinal, tallowy, fruity and mushroom notes. On the other hand, aroma compounds 2-methylpropanal, 3methylbutanal, 2-octanone, methional, methanethiol and acetic, butanoic and octanoic acids increase intensifying the green, herbal, floral, cooked-potato, rotten, vinegar and cheesy odors. These changes in aroma compounds affect consumer preferences in aroma and overall quality and overall preference for high fat sausages (Olivares et al., 2011).

\subsection{Curing agents}

As reported above the use of nitrite curing agent on meat product aroma cannot be attributed to the formation of a specific aroma compound producing the "cured odor". Its effect on aroma is a balance between aldehyde compounds (green odor notes) formed during oxidation reactions and sulfur key odor compounds producing meaty odors (Thomas et al., 2013, 2014). However, few studies have dealt with the effect of curing agent reduction on the aroma development in meat products.

A recent study by Hospital et al., (2015) has reported an effect on volatile formation in dry sausages with reduced nitrate and nitrite additions. These reduced nitrite/nitrate sausages contained the highest amounts of volatile compounds derived from carbohydrate fermentation and amino acid degradation reactions probably produced by the increased growth of Gram-positive catalase-positive cocci and Enterobacteriaceae. However, the effect on aroma compounds has been poorly described.

Nevertheless, the effect of using nitrate versus nitrite on key aroma compounds in dry sausages has been elucidated (Marco et al., 2007). In general a similar qualitative aroma profile was observed in both sausages although nitrite sausages had high aroma values for ethanol, 1-hexanol, propanoic acid, (E)-2-heptenal, and nonanal, while nitrate sausages had high aroma values for phenylacetaldehyde and 3methylbutanal (Marco et al., 2007). Nevertheless, the generation of these aroma compounds depends not only on the type of curing agent used but also on the fermentation conditions such as the use of fast or slow fermentation processes (Marco, Navarro \& Flores, 2008).

\section{Conclusions}

Remarkable progress has been made in the elucidation of key aroma compounds in cured meat products. The use of olfactometry techniques and mass spectrometry has 
allowed the identification of the main odors belonging to different chemical classes. Among the key odorants, the impact of sulfur and nitrogen containing compounds in meat product aroma is relevant producing characteristic aroma notes. Current health trends towards decreased salt, nitrites, nitrates and fat content, may require changes to the composition to some meat products. Reformulation strategies require a clear understanding of the synergies and interactions between the composition of the meat matrix and processing on aroma generation and flavor release. Finally, searching for natural strategies based on aroma precursors and biotechnology processes are essential for obtaining meat products with high aroma quality.

\section{Acknowledgements}

Financial support from AGL 2015-64673-R from MINECO (Spain) and FEDER funds are fully acknowledged.

\section{References}

Aaslyng M.D., Vestergaard C., \& Koch A.G. (2014) The effect of salt reduction on sensory quality and microbial growth in hotdog sausages, bacon, ham and salami. Meat Science, 96, 47-55.

Alahakoon, A. U., Jayasena, D. D., Ramachandra, S., \& Jo, C. (2015). Alternatives to nitrite in processed meat: Up to date. Trends in Food Science and Technology, 45, 37-49.

Alves dos Santos B., Bastianello Campagnol P.C., Bittencourt Fagundes M., Wagner R., \& Rodrigues Pollonio M.A. (2015). Generation of volatile compounds in Brazilian low-sodium dry fermented sausages containing blends of $\mathrm{NaCl}, \mathrm{KCl}$, and $\mathrm{CaCl} 2$ during processing and storage. Food Research International, 74, 306-314.

Ardö Y. (2006) Flavour formation by amino acid catabolism. Biotechnology Advances, 24, 238-242.

Armenteros M., Toldrá, F., Aristoy M.C., Ventanas J., \& Estévez M. (2012) Effect of the partial replacement of sodium chloride by other salts on the formation of volatile compounds during ripening of dry-cured ham. Journal of Agricultural and Food Chemistry. 60, 7607-7615.

Barendse, W. (2014). Should animal fats be back on the table? A critical review of the human health effects of animal fat. Animal Production Science, 54, 831-855.

Benet, I., Guàrdia, M. D., Ibañez, C., Solà, J., Arnau, J., \& Roura, E. (2016). Low intramuscular fat (but high in PUFA) content in cooked cured pork ham decreased Maillard reaction volatiles and pleasing aroma attributes. Food Chemistry, 196, 7682. 
Blank, I., Devaud, S., Fay, L. B., Cerny, C., Steiner, M., \& Zurbriggen, B. (2001). Odoractive compounds of dry-cured meat: Italian-type salami and Parma ham. In ACS Symposium Series, vol. 794 (pp. 9-20).

Brinckmann, M. Food Report (2017) -Meat Products and Sausages. Statista Consumer Market Outlook- Segment Report. Statista, Hamburg (Germany). www.statista.com.

Campo, M. M., Nute, G. R., Wood, J. D., Elmore, S. J., Mottram, D. S., \& Enser, M. (2003). Modelling the effect of fatty acids in odour development of cooked meat in vitro: Part I - Sensory perception. Meat Science, 63(3), 367-375.

Carrapiso, A. I., Jurado, Á., Timón, M. L., \& García, C. (2002). Odor-active compounds of Iberian hams with different aroma characteristics. Journal of Agricultural and Food Chemistry, 50(22), 6453-6458.

Chevance, F. F. V., \& Farmer, L. J. (1999a). Identification of major volatile odor compounds in frankfurters. Journal of Agricultural and Food Chemistry, 47(12), 5151-5160.

Chevance, F. F. V., \& Farmer, L. J. (1999b). Release of volatile odor compounds from full-fat and reduced-fat frankfurters. Journal of Agricultural and Food Chemistry, 47(12), 5161-5168.

Chevance, F. F. V., Farmer, L. J., Desmond, E. M., Novelli, E., Troy, D. J., \& Chizzolini, R. (2000). Effect of some fat replacers on the release of volatile aroma compounds from low-fat meat products. Journal of Agricultural and Food Chemistry, 48(8), 34763484.

Corral S., Salvador A., \& Flores M. (2015) Comparison of different extraction techniques for identification of key aroma compounds in traditional dry fermented sausages. Journal of the Science of Food and Agriculture, 95, 1350-1361.

Corral, S., Leitner, E., Siegmund, B., \& Flores, M. (2016). Determination of sulphur and nitrogen compounds during the processing of dry fermented sausages and their relation to amino acid generation. Food Chemistry, 190, 657-664.

Corral, S., Salvador, A., \& Flores, M. (2013). Salt reduction in slow fermented sausages affects the generation of aroma active compounds. Meat Science, 93(3), 776-785.

d'Acampora Zellner, B., Dugo, P., Dugo, G., \& Mondello, L. (2008). Gas chromatography-olfactometry in food flavour analysis. Journal of Chromatography $A$, 1186(1-2), 123-143.

De Mey, E., De Maere, H., Paelinck, H., \& Fraeye, I., (2015). Volatile N-nitrosamines in meat products: Potential precursors, influence of processing, and mitigation strategies. Critical Reviews in Food Science and Nutrition, 57, 2909-2923. 
Delahunty, C. M., Eyres, G., \& Dufour, J. P. (2006). Gas chromatography-olfactometry. Journal of Separation Science, 29(14), 2107-2125.

Desmond, E. (2006). Reducing salt: A challenge for the meat industry. Meat Science, 74 (1), 188-196.

Dunkel, A., Steinhaus, M., Kotthoff, M., Nowak, B., Krautwurst, D., Schieberle, P. \& Hofmann, T. (2014) Nature's chemical signatures in human olfaction: a foodborne perspective for future biotechnology. Angewandte Chemie International, 53, 7124 7143.

Elmore, J. S., Campo, M. M., Enser, M., \& Mottram, D. S. (2002). Effect of lipid composition on meat-like model systems containing cysteine, ribose, and polyunsaturated fatty acids. Journal of Agricultural and Food Chemistry, 50(5), 11261132.

Elmore, J. S., Mottram, D. S., Enser, M., \& Wood, J. D. (1999). Effect of the polyunsaturated fatty acid composition of beef muscle on the profile of aroma volatiles. Journal of Agricultural and Food Chemistry, 47(4), 1619-1625.

Feiner, G. 2006. Additives: proteins, carbohydrates, fillers and other additives. In: Feiner, G. (Ed.) Meat products handbook. Practical science and technology, Woodhead Publishing Limited, Cambridge, England, pp 89-141.

Fernández-Ginés JM., Fernández-López J., Sayas-Barberá, E., \& Pérez-Alvarez JA. (2005) Meat Products as Functional Foods: A Review. Journal of Food Science, 70, R37-R43.

Flores M. \& Corral S. (2017) Olfactometry detection of aroma compounds. In L. Nollet \& F. Toldrá (Eds), Advances in Food Diagnostics, 2nd edition (pp 379-400), Ames, IOWA, USA, Wiley- Blackwell Publishing.

Flores M. \& Olivares A. (2015) Flavor. In: Fidel Toldrá (Ed) Handbook of Fermented Meat and Poultry, Second Edition. (pp 217-225), John Wiley \& Sons, Ltd.

Flores M. (2016) Sausages and Comminuted Products: Cooked Sausages. In: Caballero, B., Finglas, P., and Toldrá, F. (eds.) The Encyclopedia of Food and Health vol. 4, (pp. 722-727). Oxford: Academic Press.

Flores, M. (2017). The eating quality of meat: III Flavour. In: F. Toldrá (Ed) Lawrie's Meat Science, 8th Edition - Elsevier. (pp 383-412) Woodhead Publishing Series in Food Science, Technology and Nutrition, Elsevier Ltd.

Flores, M., Grimm, C. C., Toldrá, F., \& Spanier, A. M. (1997). Correlations of sensory and volatile compounds of Spanish "Serrano" dry-cured ham as a function of two processing times. Journal of Agricultural and Food Chemistry, 45(6), 2178-2186.

Frank, D, Ball, A., Hughes,J., Krishnamurthy, R., Piyasiri,U., Stark, J., Watkins, P., \& Warner, R. (2016) Sensory and Flavor Chemistry Characteristics of Australian Beef: 
Influence of Intramuscular Fat, Feed, and Breed. Journal of Agricultural and Food Chemistry, 64, 4299-4311

Frank, D., Appelqvist, I., Piyasiri, U., Wooster, T. J., \& Delahunty, C. (2011). Proton Transfer Reaction Mass Spectrometry and Time Intensity Perceptual Measurement of Flavor Release from Lipid Emulsions Using Trained Human Subjects. Journal of Agricultural and Food Chemistry, 59, 4891-4903.

Frank, D., Eyres, G., Piyasiri, U., Delahunty, C., Appelqvist, I., \& Wooster, T. (2010). Flavour release in lipid rich food matrices; in-vitro and in-vivo measurement using proton transfer reaction mass spectrometry. Special publication - Royal Society of Chemistry, 326, 233-245.

Frank, D., Kaczmarska, K., Paterson, J., Piyasiri, U., \& Warner, R. (2017). Effect of marbling on volatile generation, oral breakdown and in mouth flavor release of grilled beef. Meat Science, 133, 61-68.

Frank, D., Oytam, Y., \& Hughes, J. (2017). Chapter 27 - Sensory Perceptions and New Consumer Attitudes to Meat A2 - Purslow, Peter P. In New Aspects of Meat Quality, (pp. 667-698): Woodhead Publishing.

Gassara, F., Kouassi, A.P., Kaur Brar, S., \& Belkacemi, K., (2016) Green alternatives to nitrates and nitrites in meat-based products-a review. Critical Reviews in Food Science and Nutrition, 56, 2133-2148.

Gianelli, M. P., Olivares, A., \& Flores, M. (2011). Key aroma components of a dry-cured sausage with high fat content (Sobrassada). Food Science and Technology International, 17(1), 63-71.

Grosch, W. (2001). Evaluation of the key odorants of foods by dilution experiments, aroma models and omission. Chemical Senses, 26(5), 533-545.

Hidalgo F.J. \& Zamora R. (2016) Amino acid degradations produced by lipid oxidation products. Critical Reviews in Food Science and Nutrition, 56, 1242-1252.

Hidalgo, F. J., \& Zamora, R. (2004). Strecker-type degradation produced by the lipid oxidation products 4,5-epoxy-2-alkenals. Journal of Agricultural and Food Chemistry, 52(23), 7126-7131.

Hospital, X.F., Carballo, J., Fernández, M., Arnau, J., Gratacós, M., \& Hierro, E. (2015) Technological implications of reducing nitrate and nitrite levels in dry-fermented sausages: Typical microbiota, residual nitrate and nitrite and volatile profile. Food Control, 57, 275-581.

Inguglia E., Zhang Z., Tiwari B.K., Kerry J.P., \& Burgess C.M. (2017) Salt reduction strategies in processed meat products - A review. Trends in Food Science \& Technology, 59, 70-78. 
Jaenkea, J., Barzia, F., McMahona, E., Webster, J. \& Brimblecombe, J. (2017). Consumer acceptance of reformulated food products: A systematic review and metaanalysis of salt-reduced foods. Critical Reviews in Food Science and Nutrition, 3357-3372.

Jelén H.H., Majcher, M. \& Dziadas M. (2012) Microextraction Techniques in the Analysis of Food Flavor Compounds: A Review. Analytica Chimica Acta, 738, 13- 26. Koutsidis, G., Elmore, J.S., Oruna-Concha, M.J., Campo, M.M., Wood, J.D., \& Mottram. D.S. (2008) Water-soluble precursors of beef flavour. Part II: Effect of postmortem conditioning. Meat Science, 79, 270-277.

Liu S.Q. (2003) Practical implications of lactate and pyruvate metabolism by lactic acid bacteria in food and beverage fermentations. International Journal of Food Microbiology, 83, 115-131.

Lorido L., Estévez, M., Ventanas J., \& Ventanas S. (2015) Salt and intramuscular fat modulate dynamic perception of flavour and texture in dry-cured hams. Meat Science 107, 39-48.

Marco, A., Navarro, J. L., \& Flores, M. (2007). Quantitation of selected odor-active constituents in dry fermented sausages prepared with different curing salts. Journal of Agricultural and Food Chemistry, 55(8), 3058-3065.

Marco, A., Navarro, J. L., \& Flores, M. (2008) The sensory quality of dry fermented sausages as affected by fermentation stage and curing agents. European Food Research and Technology. 226, 449-458.

Martínez-Arellano I., Flores M., Toldrá .F (2016) Ability of peptide extracts obtained at different dry cured ham ripening stages to bind aroma compounds. Food Chemistry, 196, 9-16.

Meynier, A., Novelli, E., Chizzolini, R., Zanardi, E., \& Gandemer, G. (1999). Volatile compounds of commercial Milano salami. Meat Science, 51(2), 175-183.

Montel, M.C., Masson, F., \& Talon, R. (1998). Bacterial role in flavour development. Meat Science, 49, 111-123.

Mottram, D. S. (1998). Flavour formation in meat and meat products: A review. Food Chemistry, 62(4), 415-424.

Muguerza, E., Gimeno, O., Ansorena, D., \& Astiasarán, I. (2004). New formulations for healthier dry fermented sausages: A review. Trends in Food Science and Technology, 15(9), 452-457.

Ockerman HW \& Basu L. (2007) Production and consumption of fermented meat products. IN: Handbook of Fermented Meat and poultry, (F Toldrá Ed), Blackwell Publishing Ltd, Ames, lowa, USA, pp 9-16. 
Olivares, A., Navarro, J. L., \& Flores, M. (2009) Establishment of the contribution of volatile compounds to the aroma of fermented sausages at different stages of processing and storage. Food Chemistry, 115, 1464-1472.

Olivares, A., Navarro, J. L., \& Flores, M. (2011). Effect of fat content on aroma generation during processing of dry fermented sausages. Meat Science, 87(3), 264273.

Ramarathnam N., Rubin L.J, \& Diosady L.L. (1993) Studies on meat flavor. 3. A novel method for trapping volatile components from uncured and cured pork. Journal of Agricultural and Food Chemistry, 41, 933-8.

Ramarathnam N., Rubin L.J., \& Diosady L.L. (1991) Studies on meat flavor. 1. Qualitative and quantitative differences in uncured and cured pork. Journal of Agricultural and Food Chemistry, 39, 344-50.

Ravyts F., Vuyst L.D., \& Leroy F. (2012) Bacterial diversity and functionalities in food fermentations. Engineering in Life Sciences. 2012, 12, 356-367.

Rodbotten, M., Kubberod, E., Lea, P., \& Ueland, O. (2004). A sensory map of the meat universe. Sensory profile of meat from 15 species. Meat Science, 68(1), 137-144.

Schmidt, S. \& Berger, R.G. (1998b). Aroma compounds in fermented sausages of different origins. Food Science and Technology-LWT, 31, 559-567.

Schmidt, S., \& Berger, R.G. (1998a). Microbially formed aroma compounds during the maturation of dry fermented sausage (Salami). Advances in Food Science, 20, 144152.

Škrlep M., Čandek-Potokar M., Batorek Lukač N., Prevolnik Povše M., Pugliese C., Labussière E., \& Flores M. (2016) The comparison of young boars and inmunocastrates for dry cured ham production under two salting regimes. Meat Science, 111, 27-37.

Söllner, K., \& Schieberle, P. (2009). Decoding the key aroma compounds of a Hungarian-type salami by molecular sensory science approaches. Journal of Agricultural and Food Chemistry, 57(10), 4319-4327.

Song, H., \& Cadwallader, K. R. (2008). Aroma components of American country ham. Journal of Food Science, 73(1), C29-C35.

Stahnke, L. H. (1994). Aroma components from dried sausages fermented with Staphylococcus xylosus. Meat Science, 38(1), 39-53.

Stahnke, L. H. (1995). Dried sausages fermented with Staphylococcus xylosus at different temperatures and with different ingredient levels - Part II. Volatile components. Meat Science, 41(2), 193-209. 
Tamm, A., Bolumar, T., Bajovic, B., \& Toepfl, S. (2016) Salt (NaCl) reduction in cooked ham by a combined approach of high pressure treatment and the salt replacer $\mathrm{KCl}$. Innovative Food Science and Emerging Technologies 36, 294-302.

Tarté, R. 2009. Ingredients in Meat Products. Properties, Functionality and Applications. Springer, New York, USA.

Théron, L., Tournayre, P., Kondjoyan, N., Abouelkaram, S., Santé-Lhoutellier, V., \& Berdagué JL. (2010) Analysis of the volatile profile and identification of odour-active compounds in Bayonne ham. Meat Science 85, 453-460.

Thomas, C., Mercier, F., Tournayre, P., Martin, J. L., \& Berdagué, J. L. (2013). Effect of nitrite on the odourant volatile fraction of cooked ham. Food Chemistry, 139(1-4), $432-438$.

Thomas, C., Mercier, F., Tournayre, P., Martin, J. L., \& Berdagué, J. L. (2014). Identification and origin of odorous sulfur compounds in cooked ham. Food Chemistry, 155, 207-213.

Thomas, C., Mercier, F., Tournayre, P., Martin, J. L., \& Berdagué, J. L. (2015). Effect of added thiamine on the key odorant compounds and aroma of cooked ham. Food Chemistry, 173, 790-795.

Toldrá F \& Flores M. (2014) Sausages, types of; Dry and semi-dry. In: C. Devine \& M. Dikeman, (Eds). Encyclopedia of Meat Sciences 2e, Vol. 3, (pp 248-255) Oxford, Elsevier.

Toldrá F \& Hui Y.H. (2015) Handbook of Fermented Meat and Poultry, Second Edition. Edited by F Toldrá and Y-H Hui. John Wiley \& Sons, Ltd.

Toldrá, F., \& Flores, M. (2006). Processed Pork Meat Flavors. In: Y.H. Hui , R. Chandan, S. Clark, N. Cross, J. Dobbs, WJ. Hurst, LM L. Nollet, E. Shimoni, N. Sinha, EB. Smith, S. Surapat, A. Titchenal, F. Toldrá, (Eds.), Handbook of Food Products Manufacturing, vol. 2. (pp. 281-301), Wiley Interscience, Hoboken, NJ, USA.

Toldrá, F., Sanz, Y., \& Flores, M. (2001). Meat fermentation technology. In: Y.H. Hui, W.K. Nip, R.W. Rogers, \& A.Y. Owen (Eds) Meat Science and Applications (pp. 537-561), Marcel Dekker: New York, USA.

van Boekel M.A.J.S. (2006) Formation of flavour compounds in the Maillard reaction. Biotechnology Advances, 24, 230-233.

Van Gemert L. and Nettenbreijer A. (2004) Compilations of odour threshold values in air and water, Boelens Aroma Chemical Information Services (BACIS), BACIS, Zeist.

Vermeulen, C., Gijs, L., \& Collin, S. (2005). Sensorial contribution and formation pathways of thiols in foods: A review. Food Reviews International, 21(1), 69-137. 
Watkins, P. J., Frank, D., Singh, T.K., Young, O.A., \& Warner, R.D. (2013). Sheepmeat flavor and the effect of different feeding systems: a review. Journal of Agricultural and Food Chemistry, 61(15), 3561-3579.

Xiao-Sheng, L., Jian-Bin, L., Zheng-Mao, Y., Huan-Lu, S., Ye L. \& Ting-Ting, Z. (2014). Aroma-active compounds in Jinhua ham produced with different fermentation periods. Molecules, 19, 19097-19113.

Ying W., Ya-Ting J., Jin-Xuan C., Yin-Ji C., Yang-Ying S., Xiao-Qun Z., Dao-Dong P., Chang-Rong O., \& Ning G. (2016) Study on lipolysis-oxidation and volatile flavour compounds of drycured goose with different curing salt content during production. Food Chemistry, 190, 33-40.

Yvon, M., \& Rijnen, L. (2001). Cheese flavour formation by amino acid catabolism. International Dairy Journal, 11, 185-201.

Zamora, R., \& Hidalgo, F. J. (2011). The Maillard reaction and lipid oxidation. Lipid Technology, 23(3), 59-62.

Zamora, R., Navarro, J.L., Aguilar, I., \& Hidalgo, F.J. (2015). Lipid-derived aldehyde degradation under thermal conditions. Food Chemistry, 174, 89-96.

Zanardi, E., Ghidini, S., Battaglia, A., \& Chizzolini, R. 2004. Lipolysis and lipid oxidation in fermented sausages depending on different processing conditions and different antioxidants. Meat Science, 66, 415-423.

Zhang W, Xiao S, Samaraweer H, Lee EJ, \& Ahn DU. (2010) Improving functional value of meat products. Meat Science, 86 15-31.

Zhang Y., Wu H., Tang J., Huang M., Zhao J., \& Zhang J. (2016) Influence of partial replacement of $\mathrm{NACL}$ with $\mathrm{KCl}$ on formation of volatile compounds in Jinhua ham during processing. Food Science and Biotechnology. 25(2): 379-391. 


\section{Figure legend}

Figure 1. Aroma wheel of wet and dry cured meat products. (adapted from Flores, 2017)

Figure 1

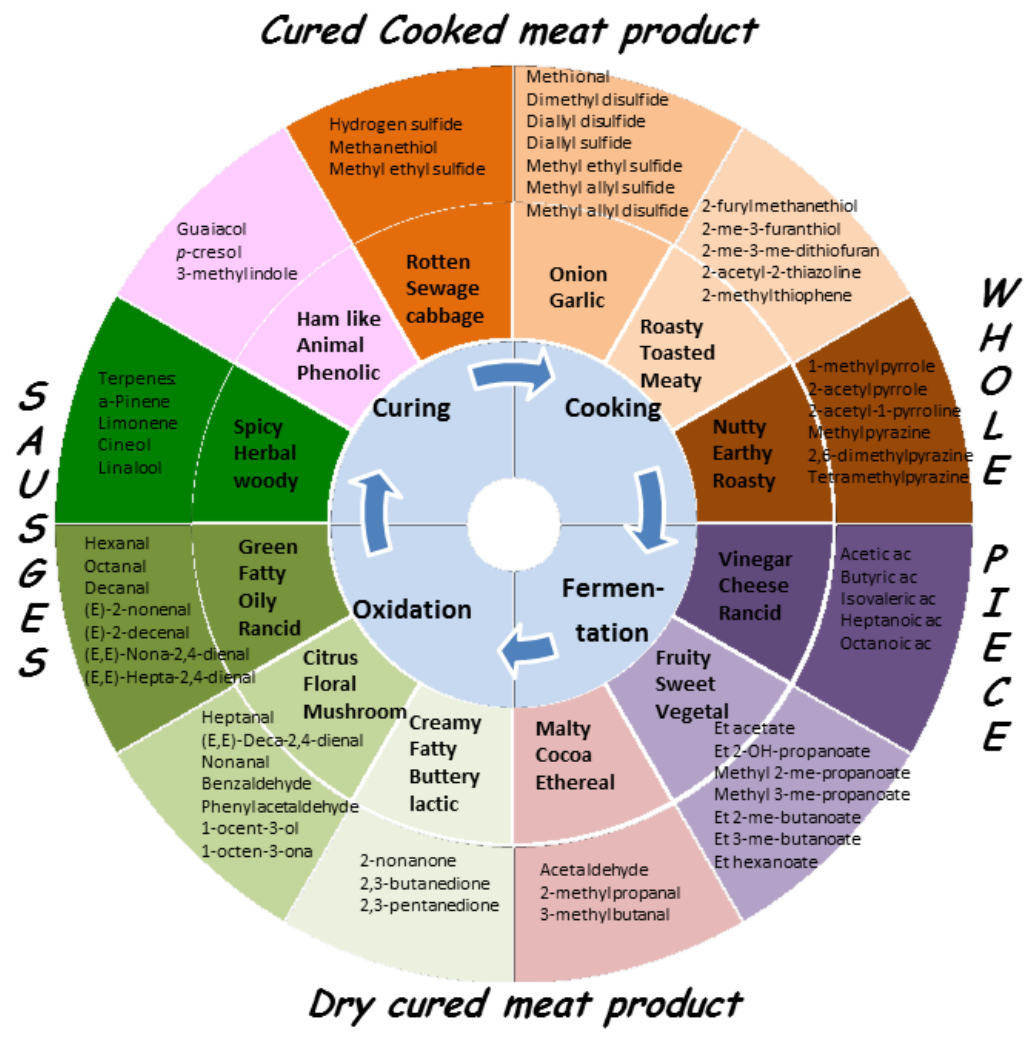


Table 1. Characteristics, crude composition and contents of wet and dry cured meat products.

\begin{tabular}{lllll}
\hline & $\begin{array}{l}\text { Cooked } \\
\text { Ham }\end{array}$ & $\begin{array}{l}\text { Cooked } \\
\text { Sausage }^{2}\end{array}$ & $\begin{array}{l}\text { Fermented } \\
\text { Sausage }^{\mathbf{3}}\end{array}$ & $\begin{array}{l}\text { Dry cured } \\
\text { Ham }^{\mathbf{4}}\end{array}$ \\
\hline Protein (\%) & $20-24$ & $10-14$ & $20-24$ & $35-40$ \\
Fat (\%) & $2-5$ & $18-35$ & $30-50$ & $6-7$ \\
Saturated fat (\%) & $1-1.6$ & $7-9$ & $12-16$ & $2.4-2.8$ \\
Moisture (\%) & $70-75$ & $50-70$ & $30-45$ & $38-48$ \\
Salt (\%) & $1.7-2.4$ & $2.0-2.5$ & $3.0-4.5$ & $4.0-6.5$ \\
Types of products & Cured & Frankfurter & Chorizo & Serrano \\
& cooked & Liver pate & Salchichón & Parma Iberian \\
& ham & Mortadella & Salami & Bayonne \\
\hline
\end{tabular}

1: Benet et al., 2016, 2: Flores, 2016 3: Ockerman \& Basu, 2007, 4: Lorido et al., 2015. 
Table 2. Mayor volatile compounds contributing to aroma and main mechanisms of formation in cooked and dry/fermented meat products.

\begin{tabular}{|c|c|c|c|c|}
\hline Chemical class & Odor description & $\begin{array}{l}\text { Average } \\
\text { threshold } \\
\text { in air } \\
(\text { ppm })^{1}\end{array}$ & $\begin{array}{c}\text { Mechanism of formation } \\
\text { in cooked meat products (wet } \\
\text { cured) }\end{array}$ & $\begin{array}{c}\text { Mechanism of formation } \\
\text { in dry and fermented meat products }\end{array}$ \\
\hline Carboxylic acids & $\begin{array}{l}\text {-Saturated acids (acidic) } \\
\text {-Unsaturated branched-chain acids } \\
\text { (pungent, sour, penetrating) } \\
\text {-Keto acids (burnt, caramel, sour) }\end{array}$ & $0.05-9$ & $\begin{array}{l}\text {-Hydrolysis of triglycerides } \\
\text { ester linkage } \\
\text {-Oxidation of fatty acids to } \\
\text { shorter chain lengths } \\
\text {-Thermal degradation of esters } \\
\text {-Autoxidation of aldehydes } \\
\text {-Autoxidation of ketones } \\
\end{array}$ & $\begin{array}{l}\text { - Microbial fermentation (branched- } \\
\text { and keto-acids) } \\
\text { - Fermentation of carbohydrates by } \\
\text { LAB }\end{array}$ \\
\hline Alcohols & $\begin{array}{l}\text {-Saturated alcohols: high threshold } \\
\text {-Straight-chain primary alcohols: } \\
\text { flavorless } \\
\text {-Increase in carbon chain: stronger } \\
\text { flavor (greenish, woody, fatty floral) } \\
\text { - Unsaturated alcohols (mushroom, } \\
\text { green-leaf, musty) }\end{array}$ & $1.0-30$ & $\begin{array}{l}\text {-Formation of aliphatic } \\
\text { alcohols from } \\
\text { oxidized lipids }\end{array}$ & $\begin{array}{l}\text {-Fermentation of carbohydrates (linear } \\
\text { alcohols) } \\
\text { - Bacterial metabolism of amino acids } \\
\text { (methyl-branched alcohols ) }\end{array}$ \\
\hline $\begin{array}{l}\text { Esters } \\
\qquad \mathrm{R}^{\prime}\end{array}$ & $\begin{array}{l}\text {-Esters from C1-C10 acids (fruity } \\
\text { sweet) } \\
\text {-Esters from long-chain fatty acids (fatty } \\
\text { flavor) }\end{array}$ & $0.001-1$ & $\begin{array}{l}\text {-Esterification of alcohols and } \\
\text { carboxylic acids present in } \\
\text { meats from chemical reactions }\end{array}$ & $\begin{array}{l}\text {-Esterase activity of microorganisms } \\
\text { (staphylococci) }\end{array}$ \\
\hline $\begin{array}{c}\text { Aldehydes } \\
H_{V}\end{array}$ & $\begin{array}{l}\text {-C3 and C4 (sharp and irritating) } \\
\text {-C5-C9 (green, oily, fatty, tallow) } \\
\text {-C10-C12 (citrus, orange peel) } \\
\text {-Alkyl-branched aldehydes (malty) }\end{array}$ & $0.01-0.1$ & $\begin{array}{l}\text {-Derived from oxidation of } \\
\text { unsaturated fatty acids } \\
\text { catalyzed by metals } \\
\text {-Alkyl-branched aldehydes } \\
\text { derived from Strecker } \\
\text { degradation of amino acids }\end{array}$ & $\begin{array}{l}\text {-Oxidation of lipids } \\
\text { - Bacterial metabolism of amino acids } \\
\text { (methyl-branched aldehydes) }\end{array}$ \\
\hline 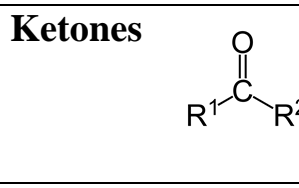 & $\begin{array}{l}\text {-Unsaturated ketones (animal fat odors) } \\
\text {-2-Alkanones (spicy, fruity, fatty, citrus- } \\
\text { like) }\end{array}$ & $0.05-100$ & $\begin{array}{l}\text {-Thermal oxidation of saturated } \\
\text { fatty acids }\end{array}$ & $\begin{array}{l}\text { - Microbial activity through lipid } \beta \text { - } \\
\text { oxidation reactions and production of } \\
\text { methyl ketones } \\
\text { - Oxidation of lipids }\end{array}$ \\
\hline
\end{tabular}




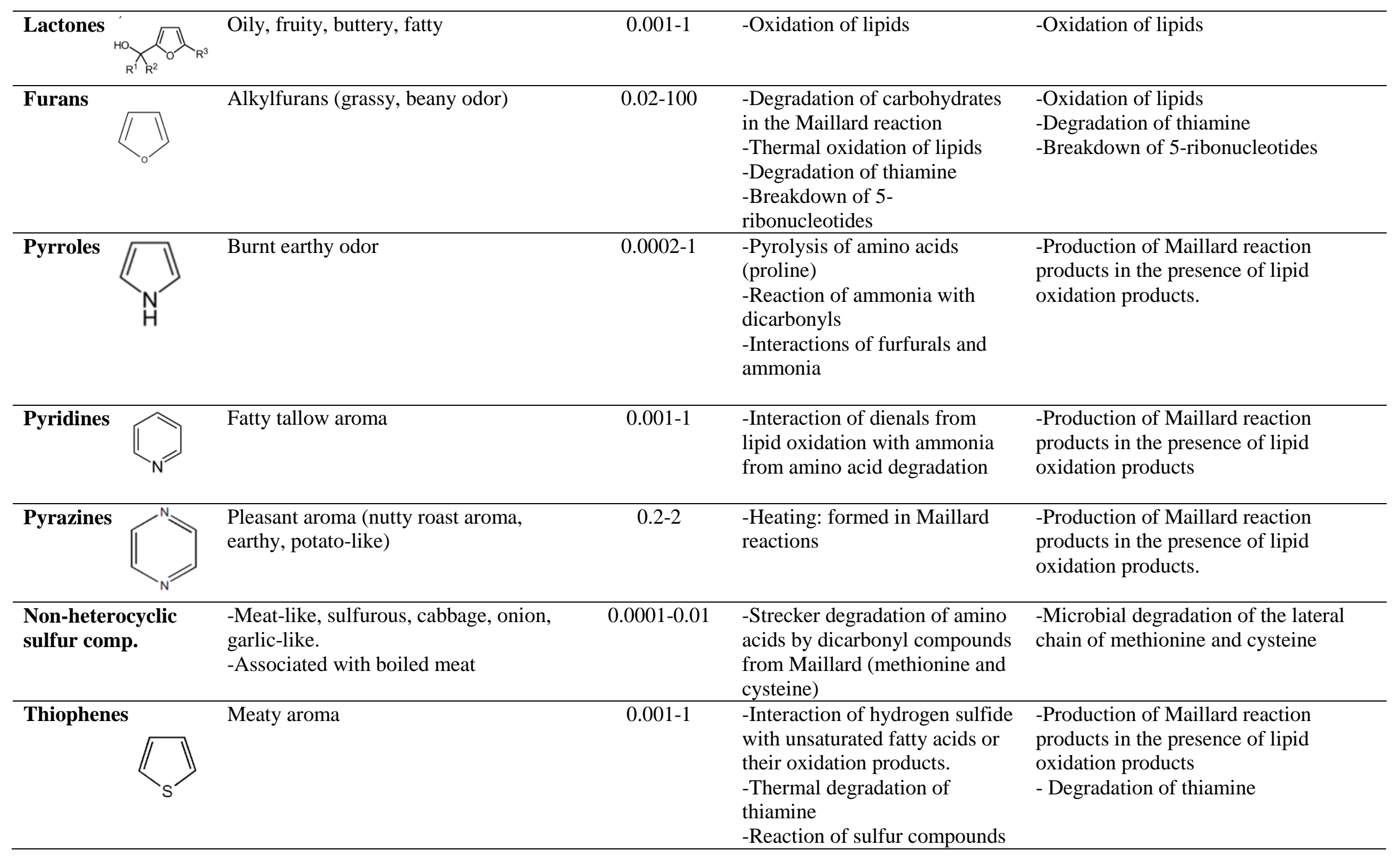


from sulfur amino acids with

sugar degradation products

from Maillard reaction

Thiazoles

Green, vegetable-like, nutty, roasted

$0.0001-0.004$

radation of thiamine.

-Interaction of hydrogen sulfide

and ammonia with aliphatic

-Production of Maillard reaction

aldehydes and dicarbonyl

oxidation products.

compounds

-Degradation of thiamine

1: Odor threshold in air by Van Gemert and Nettenbreijer (2004). 
Table 3 . Key aroma compounds (nitrogen and sulfur containing compounds) detected in meat products by olfactometry analysis (GOO) and odor description.

\begin{tabular}{|c|c|c|c|c|c|c|}
\hline \multirow[b]{2}{*}{ Chemical group } & \multirow[b]{2}{*}{ Descriptor by GC-O } & \multirow[b]{2}{*}{ Origin $^{c}$} & \multicolumn{2}{|c|}{ Cooked products $^{\mathrm{a}}$} & \multicolumn{2}{|l|}{ Dry products $^{b}$} \\
\hline & & & $\begin{array}{l}\text { Cooked } \\
\text { ham }\end{array}$ & $\begin{array}{l}\text { Cooked } \\
\text { Sausage }\end{array}$ & $\begin{array}{l}\text { Fermented } \\
\text { Sausage }\end{array}$ & $\begin{array}{l}\text { Dry cured } \\
\text { ham }\end{array}$ \\
\hline \multicolumn{7}{|l|}{ Sulphur compounds } \\
\hline Methional & Onion, cooked-potato, meat, broth, savory & Aac & 12,13 & 17,18 & $7,8,9,10,11,16$ & $19,20,21$ \\
\hline Dimethyl disulfide & Garlic, caramel, bouillon, toasted & $\mathrm{Aac}$ & 12 & & 4,10 & 14,20 \\
\hline Dimethyl trisulfide & Cabbage, sulfur & Aac & 12 & 17,18 & 6 & $19,20,21$ \\
\hline Diallyl sulfide & Garlic & Spices & & & 4,5 & \\
\hline Diallyl disulfide & Garlic & Spices & & & 4,5 & \\
\hline Methyl ethyl sulfide & Rotten onion & Spices & & & 11 & \\
\hline Methyl ethyl disulfide & Onion, pungent & Spices & & & 1 & \\
\hline Methyl allyl sulfide & Garlic & Spices & & & $1,3,4,5,9$ & \\
\hline Methyl allyl disulfide & Garlic & Spices & & & 4 & \\
\hline Dipropyltrisulfide & Meaty, bread, toasted & Spices & & & 3 & \\
\hline bis(2-methyl-3-furyl)disulfide & Cooked meat-like & Thia & 12 & & 9 & \\
\hline \multicolumn{7}{|l|}{ Thiols } \\
\hline Hydrogen sulfide & Rotten eggs, sewage & $\mathrm{Aac}$ & & & & 15 \\
\hline Methanethiol & Rotten eggs, cauliflower & Aac & 12 & & 8 & $15,20,21$ \\
\hline Ethanethiol & sulfurous & Aac & 12 & & & \\
\hline 2-Furylmethanthiol & Roasty, sulfurous, meaty & Thia, 5’R & 13 & 17,18 & 9 & \\
\hline 2-Methyl-3-furanthiol & Roasted meat, cooked meaty, cured ham & Thia, $5^{\prime} \mathrm{R}$ & 12 & 17,18 & 6,9 & 15 \\
\hline 2-Methyl-3-methyl-dithiofuran & Meaty, roasty, biscuity, ham & Thia, $5^{\prime} \mathrm{R}$ & 12,13 & 17,18 & 6 & 21 \\
\hline \multicolumn{7}{|l|}{ Thiazolines } \\
\hline 2-Acetyl-2-thiazoline & Roasty, popcorn-like, meaty & Thia & 13 & 17,18 & 9 & 20 \\
\hline \multicolumn{7}{|l|}{ Thiophene } \\
\hline 2-Methylthiophene & Sulfurous, onion, roasted & Thia, Maill & 12 & & & \\
\hline
\end{tabular}




\begin{tabular}{|c|c|c|c|c|}
\hline \multicolumn{5}{|l|}{ Pyrrole derived } \\
\hline Pyrrole & Coffee, sweet & Aac & 16 & 14 \\
\hline 1-Methylpyrrole & toasted, boullion & $\mathrm{Aac}$ & 10 & \\
\hline 2-Acetylpyrrole & Roasted nuts, fried snacks & Aac & 10,16 & \\
\hline 2-Acetyl-1-pyrroline & Roasty, popcorn, cured ham & $\mathrm{Aac}$ & $7,9,16$ & $15,20,21$ \\
\hline 2-Propionyl-1-pyrroline & Stew-like, boiled & & & 15 \\
\hline \multicolumn{5}{|l|}{ Pyrazines } \\
\hline Methylpyrazine & Nutty & Aac & & 14 \\
\hline Dimethylpyrazine & Coffee, toasted & Aac, Maill 13 & 2,16 & $14,19,20$ \\
\hline 2-Ethyl-3,5(6)-dimethylpyrazine & Earthy & Maill & 9 & \\
\hline Tetramethylpyrazine & Toasted sugar & Maill & 10 & $19,20,21$ \\
\hline 2,3-Diethyl-5-methylpyrazine & Earthy & Maill & 9 & \\
\hline 3-Isopropyl-2-methoxypyrazine & Earthy, pea-like & Maill & 9 & 21 \\
\hline 3-Isobutyl-2-methoxypyrazine & Earthy, pea-like & Maill & 9 & \\
\hline \multicolumn{5}{|l|}{ Indoles } \\
\hline 3-Methylindole & Naphthalene & Aac & 5 & \\
\hline
\end{tabular}

${ }^{a}$ Compounds detected in references: Cooked ham: 12 Thomas et al. 2013, 2014; 13 Benet et al. 2016; Cooked sausage: 17 Chevance \& Farmer 1999a; 18 Chevance \& Farmer 1999a.

${ }^{\mathrm{b}}$ Compounds detected in references: Fermented sausage: 1 Stahnke 1994; 2 Stahnke 1995; 3 Meynier et al. 1999; 4 Schmidt \& Berger 1998a; 5 Schmidt \& Berger 1998b; 6 Chevance et al. 2000; 7 Blank et al. 2001; 8 Marco et al. 2007; 9 Söllner \& Schieberle 2009; 10 Gianelli et al. 2011; 11 Olivares et al. 2011; 16 Corral et al. 2016. Dry cured ham: 14 Flores et al. 1997; 15 Carrapiso et al. 2002; 19 Theron et al. 2010; 20: XiaoSheng et al. 2014; 21 Song \& Cadwallader 2008.

${ }^{\mathrm{c}}$ Possible origin of compounds derived from: Thia: degradation of thiamin; Aac: degradation of amino acids; 5'Rib: breakdown of 5'ribonucleotides, Maill: degradation of carbohydrates in the Maillard reaction; Spices: added spices. 
